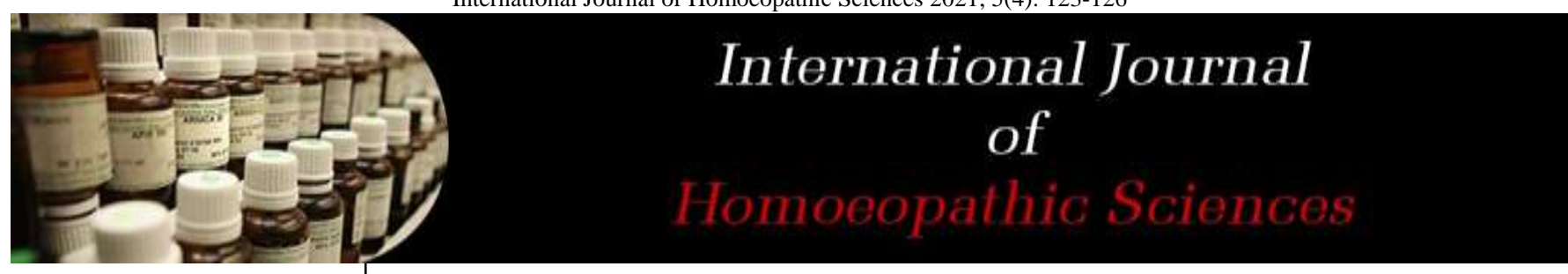

E-ISSN: $2616-4493$ P-ISSN: 2616-4485 www.homoeopathicjournal.com IJHS 2021; 5(4): 123-126 Received: 15-08-2021 Accepted: 19-09-2021

Dr. Shrishail M Murgod Professor and Hod, Department of Materia Medical Shri Shiv Basav Jyoti Homoeopathic Medical College and Hospital, Ram Nagar, Belagavi, Karnataka, India
Corresponding Author: Dr. Shrishail M Murgod Professor and Hod, Department of Materia Medical Shri Shiv Basav Jyoti Homoeopathic Medical College and Hospital, Ram Nagar, Belagavi, Karnataka, India

\section{Tinea corporis and homoeopathic management}

\author{
Dr. Shrishail M Murgod
}

DOI: $\underline{\text { https://doi.org/10.33545/26164485.2021.v5.i4b.461 }}$

\section{Abstract}

Homoeopathic cure is based on law of similar, and selection of remedy is based on Constitutional approach in management of any disease. Where the modern system of medicines makes the usage of external applications like ointments, fungicides etc. In treatment of any skin infections like ringworm or tinea corporis infection, which leads to suppression or palliation. So the disease tends to recur often and becomes a chronic disease. Removal of local symptoms of the local direction by external application leads to rousing up the internal disease and the other symptoms that previously existed in a latent state side by side with the local affection. So there is a wide scope for proper management and treatment of Tinea corporis in Homoeopathy. As in our system of medicine we do not treat the disease but we treat the individual who is suffering. Through individualization with constitutional remedy (Approach) we can treat both acute as well as the chronic phase of disease, to prevent further recurrence and complications of the disease.

Keywords: Tinea corporis, constitutional approach, homoeopathic medicines, suppression, palliation, external applications

\section{Introduction}

The constitutional homoeopathy refers to the treatment of a person as a whole, including past and present symptoms. When accurately implemented, homoeopathic constitutional care can elicit a profound healing response. Homoeopathy can be extremely effective in treating chronic and long term health problems ${ }^{[1]}$. This paper aspires to know the efficacy of homoeopathic medicines in treatment of tinea corporis through constitutional approach.

\section{Homoeopathic concept of health and disease}

The mind, body and spirit are the trinity of life which is present in every organism, Harmonious flow maintains Health \& any deviation leads to disease. As correctly stated by Robert "any disturbance of this vital energy immediately show itself in lack of harmony Through the outward manifestation of our beings, in other word symptoms, when Harmonious flow is disturbed we get sickness as result and it has as its base and Inception this lack of harmony in flow of water energy through the body is manifested in Disease as It naturally developed because of disturbed vital force" Disease presents itself as sign and symptoms, which may be functional or Structural. The functional changes lead to structural changes Hence effect is to be made to correct their disease at functional.

\section{External applications in homoeopathy}

External application have no role in Homoeopathy Hahnemann strongly condemns the practice of removing the local affections from the surface of the body without curing the internal miasmatic disease. Robert in 1992 stated regarding the harm caused by external application. The local manifestations were but as outward expression of the inward and spiritual force which when disturbed expression itself in external sign, that if these external manifestations were removed by local treatment that disease was not cured, but driven into some more centrally located organism. These to express itself in some grave form ${ }^{[2]}$. Usage of modern system of medicines like external applications like ointments fungicide etc. Which leads to suppression or palliations of the disease tends to recur often and becomes chronic disease. The disease is usually chronic and it extends over month to year.

Eczematisation and lichenification may become complication features of chronic cases [3]. J.Henry Allen his Diseases and Therapeutics of the skin say that Herpes circinnatus (ringworm of the surface) is usually treated and with fair success by sepia, Rhustox, tellurium ${ }^{[4]}$. 
Dr. Huge in his manual of therapeutic say that tinea corporis treated with sepia but when he proved tellurium produce similar eruptions he and Dr. mefcaf never failed to cure tinea circinnatus hence, it appears that there is a wide scope for proper Management and treatment of tinea corporis in homoeopathy.

\section{Tinea Corporis}

Tinea corporis is the commonest clinical variety of dermatophyte infection in India. It is distributed worldwide. It is most common in tropical regions ${ }^{[5]}$.

Tinea corporis is characterized by pea sized, pale red, well defined, slightly raised macule which soon becomes scaly and tends to clear in the center as it spreads peripherally, developing Ring like or annular lesion so it is called as ringworm of the body, Herpes circinatus. The border is generally elevated during evolution, sharply defined and may present papules, vesicles and scales. Tinea corporis may appear alone or in association with the other forms of ring worm ${ }^{[6]}$. Tinea corporis is found in most parts of the world, but particularly in hot humid climates. It is most commonly seen in children and young adults, however all age groups can be infected including new born ${ }^{[7]}$.

Ringworm" is a misnomer - the infection has nothing to do with worms. Its name comes from the small, ring- or circleshaped rash that appears on the body due to infection. In ringworm of the body the rashes appear on skin regions except for the scalp groin, palms of the hand, and soles of the feet ${ }^{[8]}$.

Body Ringworm (Tinea Corporis) is a dermatophyte (fungal) infection of the face, trunk, arms, and leg ${ }^{[9]}$. Tinea corporis, also known as ringworm, is a superficial fungal infection (dermatophytosis) of the arms and legs, especially on glabrous skin; however, it may occur on any part of the body. It is similar to other forms of tinea ${ }^{[10]}$.

Tinea corporis is a superficial fungal skin infection of the body caused by dermatophytes. Tinea corporis is present worldwide. It is defined explicitly by the location of the lesions that may involve the trunk, neck, arms, and legs ${ }^{[11]}$.

Ringworm is a fungal skin infection. (It is not due to a worm as its name implies!) There are many types of fungal germs (fungi) and some can infect the skin, nails, and hair. Fungal infections are also known as 'tinea' or 'dermatophyte infections' or dermatophyte ${ }^{[12]}$.

Ringworm of the body (tinea corporis) is a rash caused by a fungal infection. It's usually a red, itchy, circular rash with clearer skin in the middle. Ringworm gets its name because of its appearance. No worm is involved ${ }^{[13]}$.

Tinea infections are commonly called ringworm because some may form a ring-like pattern on affected areas of the body. Tinea corporis, also known as ringworm of the body, tinea circinata, or simply ringworm is a surface (superficial) fungal infection of the skin ${ }^{[14]}$.

\section{Predisposing factor}

Tinea corposis may be transmitted by direct contact with other infected Individuals or by infected animals .All forms of ringworm are contagious, directly from one person to or indirectly by clothing, hats,combs, brushes,towels or other utensils. Risk factors for infection includes exposure to infected animals persons Soil, athlete, veterinarians' animal handlers ${ }^{[15]}$.

\section{Age}

Tinea corporis affects persons of all age groups but prevalence is highest in Pre-adolescent, Tinea corporis is more common in children ${ }^{[16]}$.

\section{Sex}

Tinea corporis occurs in both men and women. Women of child bearing age are more likely to develop tinea corporis as a result of their frequency of contact with infected children ${ }^{[16]}$.

\section{Pathogenesis}

Dermatophytes grow on the keratinised layers of the skin (endothrix), in which spores occur wholly within the hair and ectothrix, in which the spores are wholly without the hair; endo ectothrix, in which the spores are found both within and without. In tinea corporis the fungus is situated in and under the corneous layer giving rise to papules, pustules and desquamation, and do not ordinarily penetrate the living tissues. Fungal products may be responsible for inciting local inflammation ${ }^{[17]}$.

\section{Clinical features}

Tinea corporis often begins with pruritus, circular or oval erythematous, scaling Patch or plague that spreads centrifugally. Central clearing patch follows while an active Advance, raised border remains. That results in annular (ring) shaped plaque from which the disease derives its common name ringworm ${ }^{[18]}$.

\section{Diagnosis}

Laboratory findings for the correct diagnosis tinea corporis the spreading Ringworm with active erythematous borderspecimens for $\mathrm{KOH}$ examination should be obtained from the actively spreading border of the lesion. ${ }^{1}$ Microscopic examination of skin scrapings for fungi sessentialin dermatologic. Fungal eruptions may closely resemble dermatitis. Microscopy of potassium hydroxide-cleared skins scrapings called a $\mathrm{KOH}$ exam takes only a few minutes and is simple principle doing ${ }^{[3,17,19]}$.

\section{Homoeopathic management ${ }^{[20,21,22]}$.}

Arsenicum album: It is predominantly belongs to syphilis miasm. It has sensitivity to disorderliness or untidiness. Anxiety and fear of death. Restless disposition. Extremely chilly individual, hugs the fire in the winter, wants to be well wrapped up. Thirst is characteristic, with a desire for frequent sips of water. Prefers warm or hot drinks. Aggravated from Cold food, cold drink, cold air, wet weather. Skin: dry, scaly, bran like, dirty, white skin; herpetic eruption with itching and burning; Burning sensation in lesions. Burning pain relieved by heat.

Dulcamara: Predominant Miasm-Psora and Sycosis. Chilly patient. Catarrhal skin infections brought on or aggravated by exposure to cold, damp, rainy weather, or sudden changes in hot weather. Precipitating causes are suppressed sweats, exposure to cold, working while standing in cold water. Humid eruptions on cheek. Thick, brown, herpetic crusts on the face, forehead, temples and chin with reddish borders, bleeding when scratched. Agg. in cold wet weather. Better by external warmth.

Graphites: Predominant Miasm-Psora. It is best suited to fatty, flabby, chilly and costive people. Extreme hesitation, unable to make up her mind about anything. Chilly. Skin 
inclined to crack. Fissures deep, bleeding or oozing out a sticky fluid. Eruptions upon the ears, between fingers and toes and on various parts of the body, from which oozes a watery, transparent, sticky fluid. Warmth of bed aggravates itching. The nails are brittle, crumbling, deformed.

Natrum muriaticum: It covers all three Miasms. Suited to anaemic, chlorotic and emaciated people, emaciation is most marked about the neck, which is very thin and shrunken. Herpes about anus and on the borders of hair at the nape of neck. Eczema: raw, red, inflamed, especially in the edges of hair; \&lt; from eating too much salt, at sea shore, or from ocean voyage.

Natrium sulphuricum: Predominant Miasm-Sycosis. Chilly patient. Diseases induced by damp weather or living in damp houses; patients feel every change of weather, especially from dry to wet. Every spring skin affections reappear. Itching while undressing. Violent itching in genital organs, of scrotum, of perineum, of mons veneris with burning after scratching. Violent itching of toes, and between toes, especially on taking off shoes and stocking at night.

Petroleum: Predominant Miasm- Psora and Syphilis. Herpes: of genital organs extending to perineum and thighs; itching, redness; skin cracked, rough, bleeding; dry or moist. The skin symptoms are worse in winter, better in summer. All the eruption itches violently. He cannot rest until he scratches the skin off, when the part becomes moist, bloody, raw and inflamed.

Sepia: Predominant Miasm-Psora, Sycosis. Suited to potbellied mothers, yellow saddle across nose, irritable, women. Skin diseases developing on brunettes who suffer from chronic uterinetroubles. Herpes circinatus in isolated spots on the upper part of the body. Itching of skin; of various parts; of external genitalia; is not \&gt; by scratching, and is apt to change to burning. Herpetic eruption on lips, about mouth and nose. Ringworm-like eruption every spring.

Sulphur: Predominant Miasm-Psora. Persons who are lean, stooped-shouldered and walk and sit stooped. Orifice of the body is very red, lips bright red. Skin: itching, voluptuous; scratching \& quite; feels good to scratch (voluptuous itching) \& quot; Scratching causes burning; \&lt; from heat of bed, washing, at night.

Tellurium Metallicum: Predominant Miasm-Psora. Herpes circinatus in intersecting rings over the whole body. Body thickly covered with elevated rings of herpes circinatus. Itching of hands and feet. Herpetic spots; ringworm. Ringshaped lesions, offensive odours from affected parts. Barber \& \#39; itches. Ringworm worse on lower extremities.

Tuberculinum: It is indicated in people with light complexion and blue eyes, suffering from a tubercular diathesis. Loses flesh while eating well. Itching intense, \& it; at night when undressing, from bathing; immense quantities of white bran-like scales; oozing behind the ears, in the hair, in folds of skin with rawness and soreness; fiery red skin. Ringworm.

\section{Discussion/Conclusion}

Tinea corporis is the commonest clinical variety of dermatophyte infection in India. It is distributed worldwide. It is most common in tropical regions. Tinea Corporis manifests itself as marked itching, vesicles pustules or scaling; these vary from case to case depending upon the virulence of the fungus and sensitivity of the Individual. The modern system of medicine adopts the usage of antifungal or fungicides, externally or internally. But the side effects of this treatment outweigh benefits and is only a palliation. In our homoeopathic management as we are treating the disease of the organism as a whole with our medicines through individualizing the patient. We can successfully treat both acute as well as chronic phases of the disease Homoeopathic system is having excellent scope in treating the disease as well as preventing the Individual from further complications.

\section{Acknowledgement}

I am very much thankful to Dr Sarita $M$ bhure who helped me with my collection of references. I thank my dear wife Mrs. Priya B Bagewadi who helped me a lot for computer work and for encouragement. I also thank the management of Shri Shiv Basav Jyoti homoeopathic medical college Belagavi Karnataka India and my staff colleague.

\section{References}

1. Aggarwal BNS, Srivastava G. Practice of Dermatology10th ed: B. Jain Publisher Pvt. Ltd; New Delhi 2005, 167.

2. Allen JH. Diseases and therapeutics of the skin Reprinted edition, B. Jain Publishers Pvt. Ltd. New Delhi 1998, 182-184.

3. Ananth NR, Jayaram Paniker CK. Textbook of Microbiology. 7th Edition. Orient Longman Pvt Ltd. Chennai 2005, 612-16.

4. Boericke W. Pocket book manual of homoeopathic Materia Medica and repertory. Reprint edition.

5. Dr. Gupta R, Dr. Manchanda RK. Dermatology for homoeopath: Aling Publication Pvt. Ltd 1997, 66-69.

6. Dr. Master FJ. Homoeopathic approach to dermatology. 2nd revised edition: B. Jain publisher (p) Ltd, New Delhi 2006, 869-888.

7. Tinea corporis corporis/\#: :text=Tinea\%20corporis $\% 20$ is $\% 20 \mathrm{a} \% 20$ su International Journal of Homoeopathic Sciences http://www.homoeopathicjournal.com 279 $\sim$ perficial,with\%20characteristic $\% 20$ ring-shaped $\% 20$.

8. Ganganagar S. A clinical study of amoebic dysentery and its homoeopathic management. IOSR J Pharm Biol Sci. lesions 2017;12(1):98-102.

9. Tinea corporis. https://www.healthline.com/health/tineacorporis\#TOC_ TITLE_HDR_1 1/2/2021.

10. Tinea

https://www.merckmanuals.com/home/skin-

corporis. disorders/fungal-skin-infections/body-ringworm-tineacorporis $1 / 2 / 2021$.

11. Tinea corporis. https://en.wikipedia.org/wiki/Tinea_corporis 1/2/2021

12. Tinea corporis. https://www.ncbi.nlm.nih.gov/books/NBK544360/1/2/2 021. 
13. https://patient.info/infections/fungalnfections/ringworm-tinea-corporis $1 / 2 / 2021$

14. https://www.mayoclinic.org/diseasesconditions/ringworm-body/symptoms-causes/syc20353780 1/2/2021.

15. https://www.skinsight.com/skin-conditions/adult/tineacorporis-ringworm-of-body

16. Fitzpatrick TB, Arthurz Eisen, Irwin Freed M, Frank F. Dermatology in General 4th ed 2nd, volume: McGraw Hill; New York 1993, 2212-2217.

17. Fitzpatrick TB, Arthurz Eisen, Irwin Freed M, Frank F.Dermatology in General 2nd, Volume 4th ed: McGrawHill; New York 1993, 2212-2217.

18. Dearborn FM MD. Disease of the skin including the exanthemata Reprint edition, B. Jain Publishers Pvt. Ltd New Delhi 2002, 233-239.

19. Robert HA, MD. The principal and art of cure by Homoeopathy B. Jain Publisher Pvt. Ltd New Delhi 1992, 150-174.

20. Allen HC. Keynotes and characteristics with comparisons of the leading remedies of the materia medica; 11th impression; B. Jain Publishers Pvt. ltd, New Delhi. Page no. -concerning medicine pages 2012.

21. Bhanja KC. Constitution, Drug Picture and Treatment; $1^{\text {st }}$ ed. Published by Mrs. Santi Bhanja 38, Shubhasnagar 1st bye- lane Calcutta 28. Page no. concerning medicine pages 1971.

22. Boericke W. Pocket manual of homoeopathic materia medica. Reprint ed. B. Jain Publishers Pvt. Itd, New Delhi. Concerning Medicine Pages 1998. 